\title{
New Coarse-Grained Models of Imidazolium Ionic Liquids for Bulk and Interfacial Molecular Simulations
}

\author{
Céline Merlet ${ }^{1, *}$, Mathieu Salanne ${ }^{1, *}$, and Benjamin Rotenberg ${ }^{1}$ \\ 1 UPMC Univ Paris 06 and CNRS, UMR 7195, \\ PECSA, F-75005, Paris, France and \\ * Corresponding authors: celine.merlet@upmc.fr, mathieu.salanne@upmc.fr
}

\begin{abstract}
We introduce new coarse-grained models for two imidazolium based ionic liquids, namely 1-butyl3-methyl-imidazolium tetrafluoroborate $[\mathrm{BMI}]\left[\mathrm{BF}_{4}\right]$ and 1-ethyl-3-methylimidazolium tetrafluoroborate $[\mathrm{EMI}]\left[\mathrm{BF}_{4}\right]$, derived from the original force field of Roy and Maroncelli (J. Phys. Chem. $B$ 2010, 114, 12629-12631) representing the 1-butyl-3-methylimidazolium hexafluorophosphate $[\mathrm{BMI}]\left[\mathrm{PF}_{6}\right]$ ionic liquid. We evaluate static and dynamic properties between $298 \mathrm{~K}$ and $500 \mathrm{~K}$ and show that they agree with previous experimental and all-atom simulations studies. The models are used to conduct simulations of the liquid-vapor interface and accurately predict surface tensions at $400 \mathrm{~K}$. Capacitive properties are also examined by doing molecular dynamics simulations of the ionic liquids in contact with graphite electrodes. The obtained structures and capacitances are consistent with all-atom simulations results reported on these systems.
\end{abstract}

Keywords: molecular dynamics, surface tension, graphite, supercapacitor, electrode, force field 


\section{INTRODUCTION}

Molecular dynamics simulations appear as a key method in many fields to understand experimental observations and to predict properties which are difficult to obtain experimentally. Due to the broad range of potential applications envisioned for room temperature ionic liquids (RTILs), numerous force fields have been developed to model these liquids. Among them, several polarizable $e^{\sqrt{12 \mid 3}}$ and non polarizable $e^{4|5| 6 \mid 7}$ potentials are sufficiently accurate to predict bulk properties and to analyse the behavior of the liquid under confinement $\frac{819 \mid 10}{}$.

One major potential application for ionic liquids is their use for supercapacitors $\frac{11|12| 13}{\text {. }}$. In these systems, energy is stored at the electrode / electrolyte interface through reversible ion adsorption. The electrodes usually consist in nanoporous carbon electrodes which give relatively high energy densities. Molecular simulations in this area will help understanding the microscopic phenomena at play and designing new materials and ionic liquids to optimize energy storage. To conduct realistic molecular dynamics simulations (MD) on these complex systems, it is necessary to include an accurate description of: i) the ionic liquid, ii) the ionic liquid / electrode interactions, iii) the electrode including the microscopic structure and polarizability of the carbon atoms. In most of the recent studies, the ionic liquid and the ionic liquid / electrode interactions are represented in an appropriate way but simple model geometries are used for the electrode structures leading to underestimated capacitances in comparison with experiments involving realistic supercapacitors $\frac{1415}{15}$. To recover the correct capacitances and gain insight in the microscopic structure adopted by the liquid in the nanopores, one should include the complexity and polarizability of the carbon structure ${ }^{16}$.

Because of the high computational cost of considering the polarizability of the electrode and the large number of carbon atoms in the calculation, it is necessary to reduce the time spent on the calculation of the interaction forces. In a previous study, we showed that the recently developed coarse-grained model representing the $[\mathrm{BMI}]\left[\mathrm{PF}_{6}\right]$ ionic liquid ${ }^{17}$ is performant to predict the structural and capacitive properties of the liquid-graphite interface ${ }^{18}$. According to these considerations, an electrochemical cell was designed using this simple model for the electrolyte and carbon electrodes generated using quenched molecular dynam$\operatorname{ics}^{19}$ leading to the conclusion that this setup is appropriate for the study of supercapacitors systems ${ }^{16}$. The coarse-grained potentials that have been investigated to date perform well but all include bonded and nonbonded interaction terms $20121|22| 23|24| 25$. The capabilities of 
the rigid-body potential of $[\mathrm{BMI}]\left[\mathrm{PF}_{6}\right]^{17118}$ encouraged us to look for such simple models.

In this work, we report the development of new coarse-grained models for two imidazolium based ionic liquids, 1-butyl-3-methylimidazolium tetrafluoroborate $\left([\mathrm{BMI}]\left[\mathrm{BF}_{4}\right]\right)$ and 1-ethyl-3-methylimidazolium tetrafluoroborate $\left([\mathrm{EMI}]\left[\mathrm{BF}_{4}\right]\right)$, and show that they are able to predict accurately a number of properties. In section II, we describe the models developed and the methodology adopted. In sections III and IV, we deal with the structural and dynamic bulk properties of the ionic liquids. In section $\mathrm{V}$, we give an account of the liquid-vapor interface properties predicted. In section VI, we provide the description of the liquid-graphite interface obtained with these models.

\section{MODEL AND SIMULATION METHODS}

The model parameters for $[\mathrm{BMI}]\left[\mathrm{BF}_{4}\right]$ and $[\mathrm{EMI}]\left[\mathrm{BF}_{4}\right]$ were derived from the force field recently developed by Roy and Maroncelli for $[\mathrm{BMI}]\left[\mathrm{PF}_{6}\right]^{17}$. To ensure that the new and original parameters are as compatible as possible, we kept the changes to a minimum. In the representation adopted here, site-site interaction energies are given by the sum of a Lennard-Jones potential and coulombic interactions:

$$
u_{i j}\left(r_{i j}\right)=4 \varepsilon_{i j}\left[\left(\frac{\sigma_{i j}}{r_{i j}}\right)^{12}-\left(\frac{\sigma_{i j}}{r_{i j}}\right)^{6}\right]+\frac{q_{i} q_{j}}{4 \pi \varepsilon_{0} r_{i j}},
$$

where $r_{i j}$ is the distance between sites and $\varepsilon_{0}$ is the vacuum permittivity. A schematic view of the correspondence between atoms and interaction sites is given in figure 1 . The parameters are varied independently to match the density and diffusion coefficients of $[\mathrm{BMI}]\left[\mathrm{BF}_{4}\right]$ and $[\mathrm{EMI}]\left[\mathrm{BF}_{4}\right]$ at $400 \mathrm{~K}$. The geometry of $\mathrm{EMI}^{+}$was chosen from the centers of mass positions of the different regions of the cation in typical configurations of an all-atom model (imidazolium ring, ethyl chain, methyl chain). Charges for the $\mathrm{EMI}^{+}$cation were calculated summing the atomic charges of an all-atom non polarizable force field ${ }^{5}$ and scaling them to recover the reduced charge of 0.78 e on the ion used in the original model. The conservation of this reduced charge for all the ions is required to allow for future works on mixtures of the ionic liquids. All the interaction parameters of the coarse-grained models are summarized in table I.

We made use of three types of simulations to calculate different properties. First, bulk simulations were employed to determine densities, radial distribution functions, diffusion 
$\mathrm{BMI}^{+}$

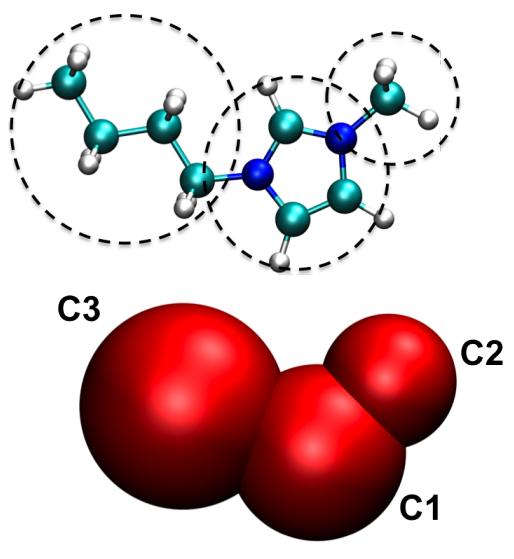

$\mathrm{EMI}^{+}$
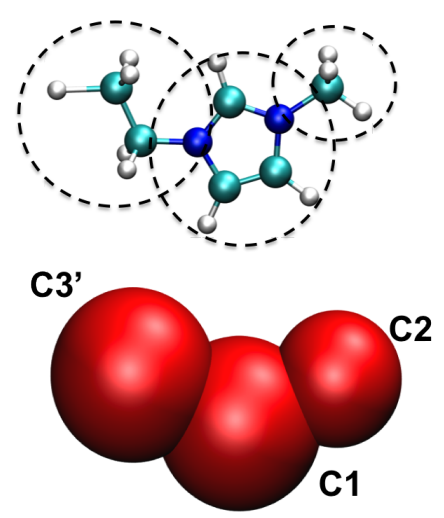

$\mathrm{BF}_{4}^{-}$
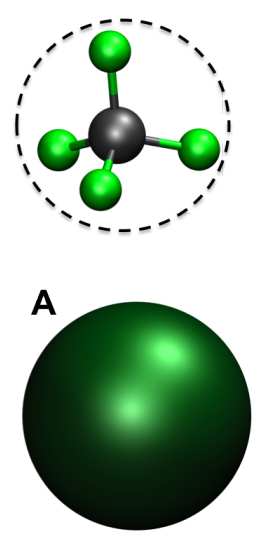

Figure 1: Schematic representations of the coarse-grained models of the three ions considered: $\mathrm{BMI}^{+}, \mathrm{EMI}^{+}$and $\mathrm{BF}_{4}^{-}$.

\begin{tabular}{|c|c|c|c|c|c|c|c|c|}
\hline $\begin{array}{c}\text { Interaction } \\
\text { site }\end{array}$ & $\begin{array}{c}\mathrm{x} \\
(\AA)\end{array}$ & $\begin{array}{c}\mathrm{y} \\
(\AA)\end{array}$ & $\begin{array}{c}\mathrm{z} \\
(\AA)\end{array}$ & $\begin{array}{c}\mathrm{M} \\
\left(\mathrm{g} . \mathrm{mol}^{-1}\right)\end{array}$ & $\begin{array}{c}\sigma_{i} \\
(\AA)\end{array}$ & $\begin{array}{c}\varepsilon_{i} \\
\left(\mathrm{~kJ}^{\mathrm{mmol}}{ }^{-1}\right)\end{array}$ & $\begin{array}{c}q_{i} \text { in } \mathrm{BMI}^{+} \\
(\mathrm{e})\end{array}$ & $\begin{array}{c}q_{i} \text { in } \mathrm{EMI}^{+} \\
(\mathrm{e})\end{array}$ \\
\hline $\mathrm{A}$ & 0.000 & 0.000 & 0.000 & 86.81 & 4.51 & 3.24 & -0.7800 & -0.7800 \\
\hline $\mathrm{C} 1$ & 0.000 & -0.527 & 1.365 & 67.07 & 4.38 & 2.56 & 0.4374 & 0.3591 \\
\hline $\mathrm{C} 2$ & 0.000 & 1.641 & 2.987 & 15.04 & 3.41 & 0.36 & 0.1578 & 0.1888 \\
\hline $\mathrm{C} 3$ & 0.000 & 0.187 & -2.389 & 57.12 & 5.04 & 1.83 & 0.1848 & - \\
\hline $\mathrm{C} 32$ & 0.000 & -0.737 & -1.653 & 29.07 & 4.38 & 1.24 & - & 0.2321 \\
\hline
\end{tabular}

Table I: Force-field parameters for $[\mathrm{BMI}]\left[\mathrm{BF}_{4}\right]$ and $[\mathrm{EMI}]\left[\mathrm{BF}_{4}\right]$. Site-site interaction energies are given by the sum of a Lennard-Jones potential and coulombic interactions $u_{i j}\left(r_{i j}\right)=4 \varepsilon_{i j}\left[\left(\frac{\sigma_{i j}}{r_{i j}}\right)^{12}-\right.$ $\left.\left(\frac{\sigma_{i j}}{r_{i j}}\right)^{6}\right]+\frac{q_{i} q_{j}}{4 \pi \varepsilon_{0} r_{i j}}$ where $r_{i j}$ is the distance between sites, $\varepsilon_{0}$ is the permittivity of free space and cross-interaction parameters are calculated by Lorentz-Berthelot mixing rules. The parameters for the carbon atoms of the graphite electrodes are $\sigma_{\mathrm{C}}=3.37 \AA$ and $\varepsilon_{\mathrm{C}}=0.23 \mathrm{~kJ} . \mathrm{mol}^{-126}$.

coefficients and viscosities. Second, simulations of the liquid-vacuum interface were used to estimate the surface tension. Finally, more complex setups were introduced to test the structural and capacitive properties of the liquid-electrode interface. For all the simulations, the timestep for the integration of the rigid body equations of motion is 2 fs. For the simulations conducted in the NVT ensemble, a weak Nosé-Hoover thermostat ${ }^{27}$ with 
a time constant of $10 \mathrm{ps}$ is employed. Electrostatic interactions were treated using a 3D or $2 \mathrm{D}$ Ewald summation according to the periodic boundary conditions adopted for each simulation type.

All the bulk properties were computed by simulations on a cubic cell containing 432 (for $[\mathrm{BMI}]\left[\mathrm{BF}_{4}\right]$ ) or 576 (for $[\mathrm{EMI}]\left[\mathrm{BF}_{4}\right]$ ) ion pairs. Cubic periodic boundary conditions were employed. When the temperature is modified, the system is allowed to equilibrate for $400 \mathrm{ps}$ in the NPT ensemble using time constants of 10 ps and 20 ps for the thermostat and barostat respectively ${ }^{28}$. At the end of this relaxation time, the equilibrated volume of the cell is used to evaluate the density of the system. The statistics for the other properties are then typically collected during $1 \mathrm{~ns}$ in the NVT ensemble. Longer simulations were used to evaluate the viscosity for temperatures under $373 \mathrm{~K}$.

Interfacial properties were calculated from simulations on orthorhombic cells with lengths such that $L_{x} \sim L_{y}<L_{z}$, according to the fact that the interface is oriented perpendicularly to the $z$ direction. For the determination of the surface tension, a slab of ionic liquid, consisting of 1280 ions pairs, is sandwiched between two vacuum regions. The entire simulation cell has the size $7.2 \mathrm{~nm} \times 7.7 \mathrm{~nm} \times 50 \mathrm{~nm}$. These values were chosen as a result of our previous work on $[\mathrm{BMI}]\left[\mathrm{PF}_{6}\right]^{18}$. The simulation is started from a configuration near equilibrium, already at $400 \mathrm{~K}$, and allowed to relax for another $400 \mathrm{ps}$ in the NVT ensemble. The statistics are then gathered for 1 ns using the same conditions.

For liquid-graphite simulations, the system consists of 320 ion pairs sandwiched between two groups of three graphite layers, a snapshot of the simulation cell is given in supporting information. The lengths in the $x$ and $y$ directions are chosen to match with the lattice parameters of graphite and are equal to $3.22 \mathrm{~nm}$ and $3.44 \mathrm{~nm}$ respectively. The length in the $z$ direction is adjusted to recover the bulk density of the ionic liquid at $400 \mathrm{~K}$ leading to $L_{z}=11.26 \mathrm{~nm}$ for $[\mathrm{BMI}]\left[\mathrm{BF}_{4}\right]$ and $L_{z}=9.68 \mathrm{~nm}$ for $[\mathrm{EMI}]\left[\mathrm{BF}_{4}\right]$. The method used to enforce a constant potential difference between the walls, as opposed to a constant charge, following the methodology of Siepmann and Sprik ${ }^{29}$, is detailed in our previous work ${ }^{18}$. This representation of the electrodes polarizability has been successfully implemented in simulations of various systems $\frac{18|30| 31 / 32] 33}{\text {. The potential difference }}\left(\Delta \Psi^{0}\right)$ is applied between the positive $\left(\Psi^{+}\right)$and negative $\left(\Psi^{-}\right)$electrodes in order to have: $\Psi^{+}=-\Psi^{-}=\frac{\Delta \Psi^{0}}{2}$. When the potential difference is modified, the system is equilibrated during 200 ps before gathering data during $1 \mathrm{~ns}$. The potential difference is increased gradually from $0.0 \mathrm{~V}$ to $1.50 \mathrm{~V}$ to 
ensure that the system is effectively equilibrated before gathering statistics. The simulations are conducted at $400 \mathrm{~K}$ in the NVT ensemble applying 2D periodic boundary conditions.

\section{BULK STATIC PROPERTIES}

Figure 2 compares densities evaluated under a pressure of 1 bar for our models with experimenta $\sqrt[663435136]{ }$ and all-atom simulations ${ }^{5}$ data. As expected, the density is larger for $[\mathrm{EMI}]\left[\mathrm{BF}_{4}\right]$ than for $[\mathrm{BMI}]\left[\mathrm{BF}_{4}\right]$ for all the studied temperatures. The agreement between experimental data and ours is fairly good, in particular, the variation with temperature is well reproduced by the coarse-grained models. For this property, our new models perform even better than the all-atom ones of Chaban and coworkers ${ }^{5}$.

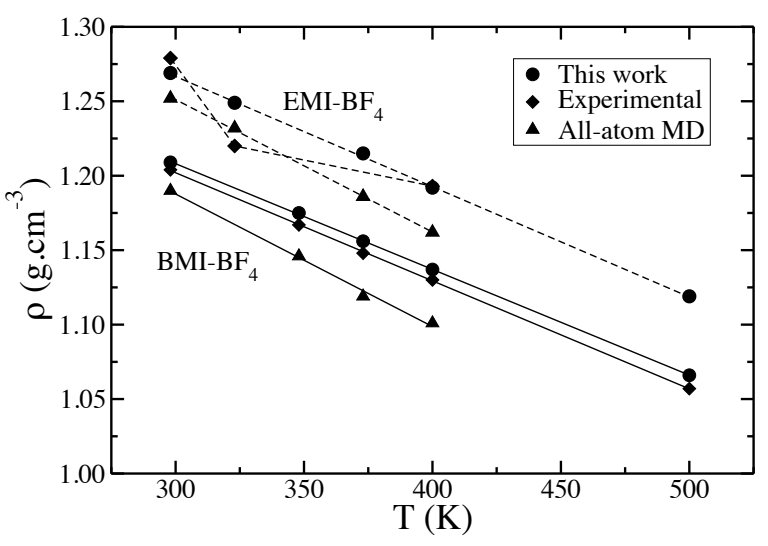

Figure 2: Comparison of densities obtained in this work with experimental ${ }^{6[34 \sqrt{35} \mid 36}$ and all-atom simulations ${ }^{5}$ data. Our coarse-grained models give results in agreement with experiments and all-atom models. In particular, the variation with temperature is well reproduced.

Then, we evaluate the radial distribution functions between anions and cations in order to assess the ability of our models to predict the local structure adopted by the liquids. The radial distribution functions, plotted in figure 3, can be compared with the ones obtained by Andrade et al.$^{37}$ and Dommert et al. ${ }^{[6}$ using all-atom models. Despite the fact that densities are different for $[\mathrm{BMI}]\left[\mathrm{BF}_{4}\right]$ and $[\mathrm{EMI}]\left[\mathrm{BF}_{4}\right]$, their radial distribution functions are very similar.

The radial distribution function between the center of mass of the anion and the imidazolium ring of the cation (site C1) presents a first peak at around $0.45 \mathrm{~nm}$ for both ionic liquids. For all-atom models, this peak is at $0.48 \mathrm{~nm}$ and $0.50 \mathrm{~nm}$ for $[\mathrm{BMI}]\left[\mathrm{BF}_{4}\right]$ 

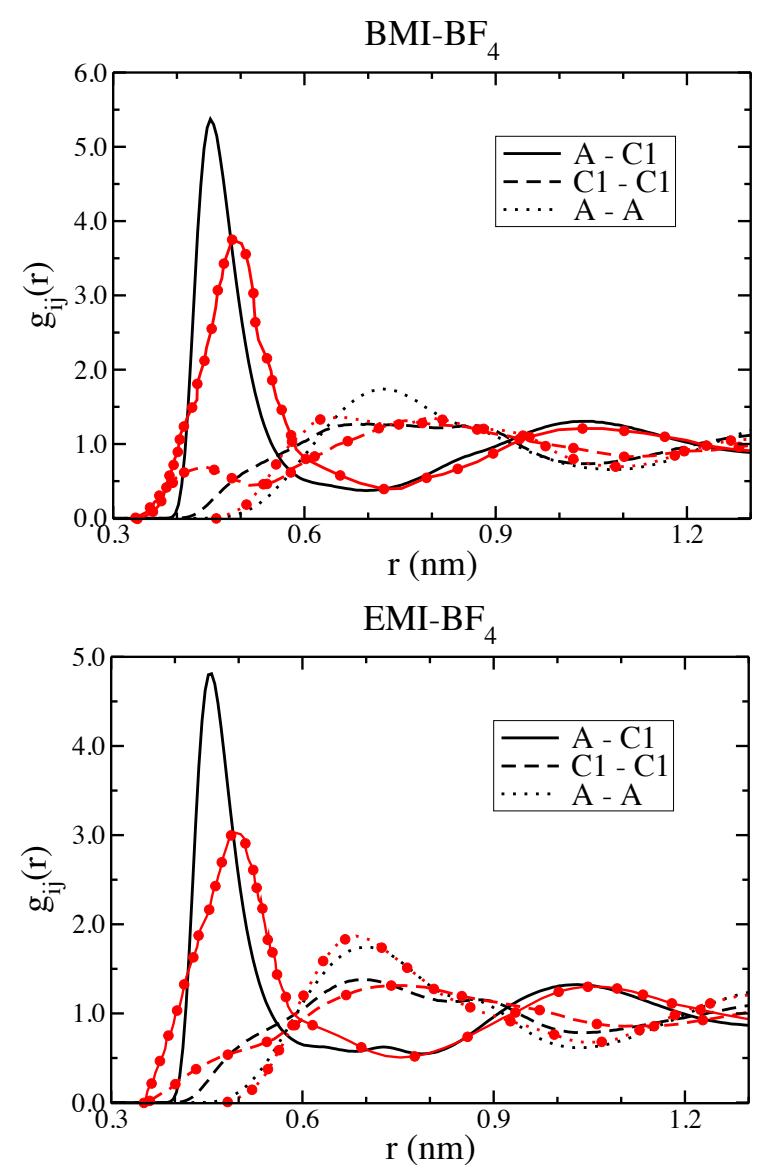

Figure 3: Radial distribution functions at $400 \mathrm{~K}$ calculated in this work for anion-anion, anioncation and cation-cation pairs. Black lines (without symbols) are results from this work, red lines (with symbols) are all-atoms models results6 637 . Some peaks characteristic of the all-atom models merge to give the resulting peaks presented here for the coarse-grained potentials.

and $[\mathrm{EMI}]\left[\mathrm{BF}_{4}\right]$ respectively. Thus, it appears that our models slightly underestimate the anion-imidazolium ring distance. Figure 3 also shows that the anion-cation peaks are wider and with a lower maximum intensity for all-atom models compared with our models.

For $[\mathrm{BMI}]\left[\mathrm{BF}_{4}\right]$, there are two others striking features in going from the all-atom model to the coarse-grained model. First, for the C1-C1 curve, the two peaks at $0.44 \mathrm{~nm}$ and $0.77 \mathrm{~nm}$ in the all-atom model merge into a single flat peak centered around $0.61 \mathrm{~nm}$, i.e. the average between these two values. Second, for the anion-anion curve, in a similar way, the peaks present at $0.64 \mathrm{~nm}$ and $0.80 \mathrm{~nm}$ merge to give a single peak at $0.72 \mathrm{~nm}$, but the resulting peak is broader. Comparable phenomena appear for the $[\mathrm{EMI}]\left[\mathrm{BF}_{4}\right]$ case.

According to the previous observations, the densities and local structure of the bulk 
systems seem to be correctly reproduced by the coarse-grained models developed in this work, keeping in mind that some structural features are averaged out as a result of the coarse-grained process.

\section{BULK DYNAMIC PROPERTIES}

We now turn to the calculation of some dynamic bulk properties of the ionic liquids and their confrontation with results from experiments and previous models. Diffusion coefficients were calculated using the Einstein relation:

$$
D_{\alpha}=\lim _{t \rightarrow \infty} \frac{1}{6 t}\left\langle\left|\boldsymbol{\delta} \boldsymbol{r}_{\boldsymbol{i}}(\boldsymbol{t})\right|^{2}\right\rangle
$$

where $\boldsymbol{\delta} \boldsymbol{r}_{\boldsymbol{i}}(\boldsymbol{t})$ is the displacement of a given ion of species $\alpha$ in time $t$ and the brackets denote an ensemble average. The diffusion coefficients obtained for different temperatures between $298 \mathrm{~K}$ and $500 \mathrm{~K}$ are given in figure 4. The coarse-grained models tend to underestimate the diffusion at low temperatures at which the ionic liquids are highly viscous. For EMI-BF 4 , the increasing gap between values at high temperatures could be explained by the fact that the experimental values are extrapolated from data gathered between $250 \mathrm{~K}$ and $380 \mathrm{~K}$. Nevertheless, the agreement is good over the range of temperatures studied.

The viscosity of the systems was determined following the Green-Kubo relation:

$$
\eta=\frac{V}{k_{B} T} \int_{0}^{\infty}\left\langle\sigma_{\alpha \beta}(0) \sigma_{\alpha \beta}(\tau)\right\rangle d \tau
$$

where $\sigma_{\alpha \beta}$ is one of the components of the stress tensor and $V$ is the simulation cell volume. As this property is a collective one, its precise evaluation is more difficult compared to diffusion coefficients.

The correlation function of the stress tensor was taken to be the mean of its five different anisotropic components. The viscosities resulting from our simulations are summarized in table II along with experimental $\sqrt{34|36| 38}$ and all-atom simulations ${ }^{5}$ data. The models are able to predict viscosities in agreement with experimental data within the range of experimental errors except at $348 \mathrm{~K}$ where this property is overestimated.

At this point, we can say that our coarse-grained models are sufficiently accurate to predict static and dynamic properties of the bulk systems for the range of temperatures studied. 

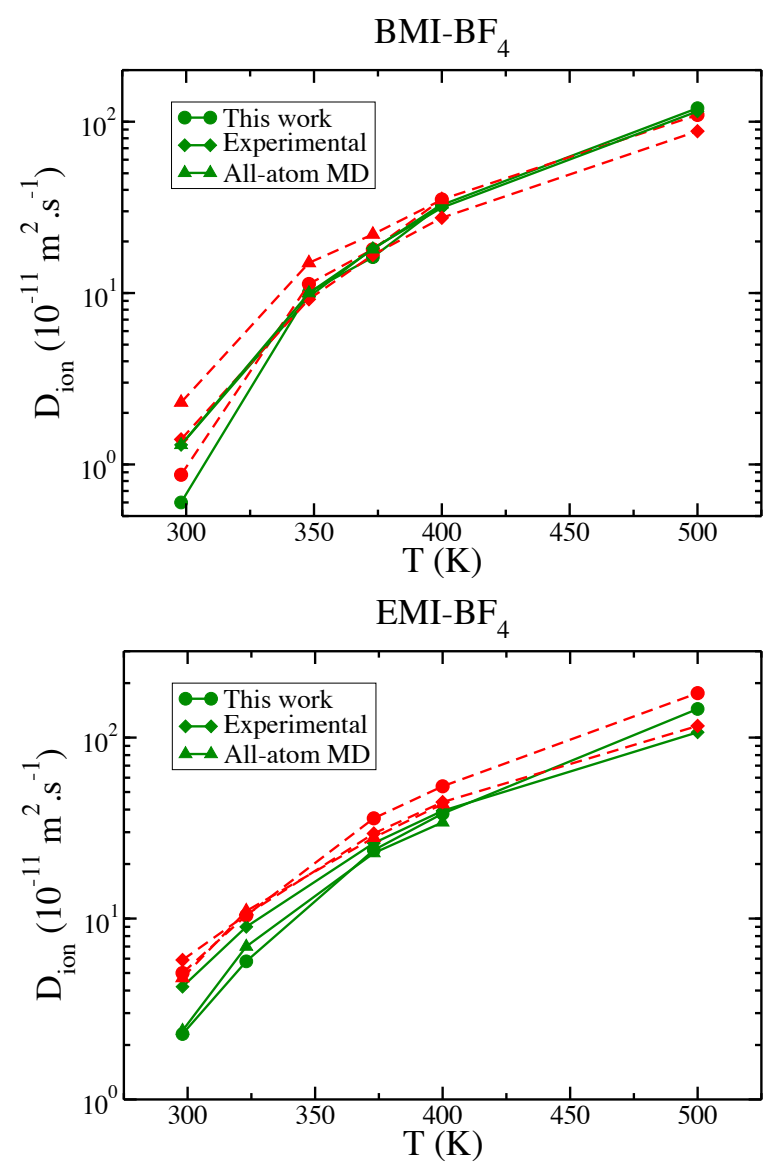

Figure 4: Diffusion coefficients obtained for our new models and comparison with experiments $34 \sqrt[36 / 38]{3}$ and all-atom simulations ${ }^{5}$. Results for anions and cations are given in green (full line) and red (dashed line) respectively.

\section{SURFACE TENSION OF THE LIQUID-VACUUM INTERFACE}

The estimation of the surface tension is a good test of the performance of a model for the prediction of interfacial properties. The surface tension is determined following a standard methodology $\sqrt{39 / 40 \mid 41}$, i.e. using simulations of a slab of ionic liquid sandwiched between two vacuum regions. The system is simulated using 3D periodic boundary conditions and Ewald summations to compute the electrostatic interactions. We demonstrated that for $[\mathrm{BMI}]\left[\mathrm{PF}_{6}\right]$, a length of $50 \mathrm{~nm}$ (including the liquid slab) in the direction perpendicular to the interface was sufficient to avoid interactions between the slabs ${ }^{18}$. As the ionic liquids studied here present similar characteristics, we assume that this length is appropriate for our present study. 


\begin{tabular}{|c|c|c|c|c|}
\hline$\eta$ (mPa.s) & $348 \mathrm{~K}$ & $373 \mathrm{~K}$ & $400 \mathrm{~K}$ & $500 \mathrm{~K}$ \\
\hline BMI-BF $_{4}$ & & & & \\
This work & 25.4 & 9.7 & 5.1 & 1.7 \\
Experimental $^{36}$ & 15.1 & 8.6 & 5.4 & 1.9 \\
All-atom MD $^{5}$ & 13.0 & 8.0 & 5.0 & - \\
\hline EMI-BF $_{4}$ & & & & \\
This work $^{2}$ & - & 7.5 & 5.3 & 1.8 \\
Experimental $^{34}$ & 8.8 & 5.8 & 4.0 & 1.7 \\
Experimental & 12.4 & 8.0 & 5.4 & 2.1 \\
All-atom MD & 10.0 & 6.0 & 4.0 & - \\
\hline
\end{tabular}

Table II: Shear viscosities calculated in this work compared to experimental data ${ }^{34|36| 38}$ and allatom molecular dynamics simulations ${ }^{5}$.

The surface tensions are derived from the stress tensor components $\sqrt[39 \mid 40]{ }$ :

$$
\gamma=\frac{L_{z}}{2}\left(\left\langle\sigma_{z z}\right\rangle-\frac{\left\langle\sigma_{x x}+\sigma_{y y}\right\rangle}{2}\right) .
$$

We obtain a value of $33.8 \mathrm{mN} \cdot \mathrm{m}^{-1}$ at $400 \mathrm{~K}$ for $[\mathrm{BMI}]\left[\mathrm{BF}_{4}\right]$ which compares well with the experimental value of $38.2 \mathrm{mN}^{-1}$ at $393 \mathrm{~K}^{42}$. The surface tension for $[\mathrm{EMI}]\left[\mathrm{BF}_{4}\right]$, $44.3 \mathrm{mN} . \mathrm{m}^{-1}$ at $400 \mathrm{~K}$, is also in agreement with the experiments giving $41.9 \mathrm{mN} . \mathrm{m}^{-1}$ at $400 \mathrm{~K}^{43}$.

\section{STRUCTURAL AND CAPACITIVE PROPERTIES OF THE LIQUID- GRAPHITE SYSTEM}

The coarse-grained models built here have proven their accuracy for a number of bulk and interfacial properties but, because the goal of this work is to develop models which can be used in simulations of supercapacitors, we need to check that the liquid / carbon interface behaves realistically. A simulation cell consisting of two graphite electrodes surrounding a slab of ionic liquid was used to test the structural and capacitive properties of the systems.

From our simulations results, we plot the ionic densities for the centers of mass of anions and cations when various potential differences are applied between the electrodes. Ionic density profiles corresponding to $\Delta \Psi^{0}=\Psi^{+}-\Psi^{-}=0.0 \mathrm{~V}$ and $\Delta \Psi^{0}=1.5 \mathrm{~V}$ are given 
in supporting information for the two liquids studied here. If we assume that applying a zero potential difference or a zero constant charge affects the ionic liquid in the same way, then we can compare the ionic density profiles for $[\mathrm{EMI}]\left[\mathrm{BF}_{4}\right]$, with $\Delta \Psi^{0}=0.0 \mathrm{~V}$, with the published results of Shim et al. 44 . Indeed, the ionic densities generated with our model of $[\mathrm{EMI}]\left[\mathrm{BF}_{4}\right]$ (see figure 5) present the same features as the ones from the all-atom simulations of Shim and coworkers $\stackrel{44}{ }$. A layering is observed at null potential difference, induced by the molecular sizes of the ions.

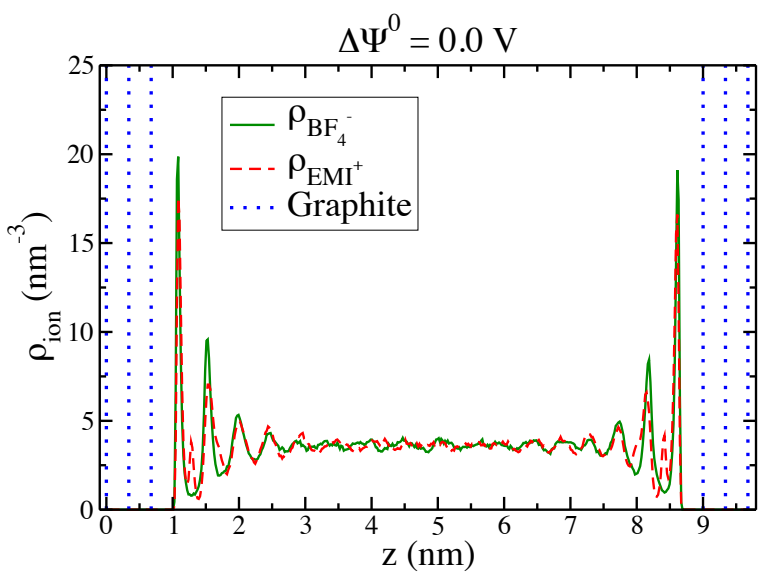

Figure 5: Ionic density profiles of the centers of mass of the anions and cations for $[\mathrm{EMI}]\left[\mathrm{BF}_{4}\right]$ when a zero potential difference is applied between the electrodes. The curves present the same features as the all-atom simulations of Shim et al $\stackrel{44}{4}$ at constant zero charge.

For both coarse-grained and all-atom models, a first peak is observed for cations and anions at the same distance from the interface with ionic densities equal to approximately 20 ions per $\mathrm{nm}^{3}$. A small peak is observed for cations at a distance around $0.25 \mathrm{~nm}$ from the first peak. The following peaks of the layered structure are separated by $0.40 \mathrm{~nm}$, a distance for which both models also agree. The comparison between the ionic density profiles when a non zero potential difference (or a non zero charge on the electrodes) is applied cannot be made because the fixed charge in their simulations is more than twice the highest fluctuating charge in our work. Nevertheless, we also observe an enhancement of the counter-ions ionic densities near the electrodes and the beginning of the alternating of anions and cations layers.

The ionic density profiles for $[\mathrm{BMI}]\left[\mathrm{BF}_{4}\right]$ are very similar to the ones of $[\mathrm{EMI}]\left[\mathrm{BF}_{4}\right]$ but the differences between anions and cations peaks are more pronounced for $[\mathrm{BMI}]\left[\mathrm{BF}_{4}\right]$, prob- 
ably because of the more important asymmetry between the ions geometries for this ionic liquid. When a potential difference of $1.5 \mathrm{~V}$ is applied, the alternating layers are more visible for $[\mathrm{BMI}]\left[\mathrm{BF}_{4}\right]$ compared to $[\mathrm{EMI}]\left[\mathrm{BF}_{4}\right]$. These small distinctions lead to differences in the capacitive properties of the ionic liquids which we now underline.

The capacitance of the ionic-liquid / graphite systems can be determined using the Poisson potential and the total charge on the electrodes. The plots showing the surface charge as a function of the potential drop for the ionic liquids studied in this work are given in figure 6. The differential capacitances are extracted from these curves using:

$$
\mathrm{C}_{\text {diff }}=\frac{\partial \sigma}{\partial \Delta \Psi}
$$

where $\sigma$ is the total charge on the electrode and $\Delta \Psi$ is the potential drop across the interface $\left(\Delta \Psi^{ \pm}=\Psi^{ \pm}-\Psi_{\text {bulk }}\right)$. As for $[\mathrm{BMI}]\left[\mathrm{PF}_{6}\right]^{[18}$, we identify two linear régimes meaning that the differential capacitances are constant over the range of potential differences studied. The capacitances are summarized in table $\mathrm{III}$ along with the results for $[\mathrm{BMI}]\left[\mathrm{PF}_{6}\right]^{18}$.

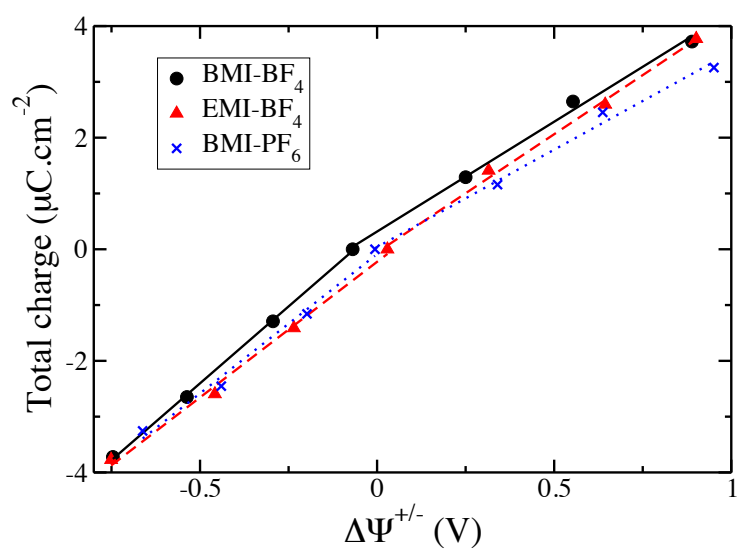

Figure 6: Surface charge as a function of the potential drop across the interface for $[\mathrm{BMI}]\left[\mathrm{BF}_{4}\right]$ and $[\mathrm{EMI}]\left[\mathrm{BF}_{4}\right]$ investigated in this work. Results for $[\mathrm{BMI}]\left[\mathrm{PF}_{6}\right]$ are given for comparison $\frac{18}{}$. The differential capacitances of the positive and negative interfaces are given by the slopes obtained in the linear régimes.

We note that the capacitances for the positive electrodes in the two tetrafluoroborate ionic liquids are very similar, in concordance with the fact that the ionic liquids share the same anion, but do differ a little. We notice that the potential of zero charge (PZC) is different for the two systems, around $-69 \mathrm{mV}$ for $[\mathrm{BMI}]\left[\mathrm{BF}_{4}\right]$ and $29 \mathrm{mV}$ for $[\mathrm{EMI}]\left[\mathrm{BF}_{4}\right]$.

The ionic liquids / graphite interfaces that we investigate here have also been studied 


\begin{tabular}{|l|l|l|}
\hline BMI-BF $_{4}$ & $\mathrm{C}_{-}=5.5 \mu \mathrm{F} . \mathrm{cm}^{-2}$ & $\mathrm{C}_{+}=3.9 \mu \mathrm{F} . \mathrm{cm}^{-2}$ \\
\hline EMI-BF $_{4}$ & $\mathrm{C}_{-}=4.9 \mu \mathrm{F} \cdot \mathrm{cm}^{-2}$ & $\mathrm{C}_{+}=4.2 \mu \mathrm{F} \cdot \mathrm{cm}^{-2}$ \\
\hline BMI-PF $_{6}$ & $\mathrm{C}_{-}=4.8 \mu \mathrm{F} \cdot \mathrm{cm}^{-2}$ & $\mathrm{C}_{+}=3.9 \mu \mathrm{F} . \mathrm{cm}^{-2}$ \\
\hline
\end{tabular}

Table III: Differential capacitances obtained in this work and comparison with published values for $[\mathrm{BMI}]\left[\mathrm{PF}_{6}\right]^{18}$.

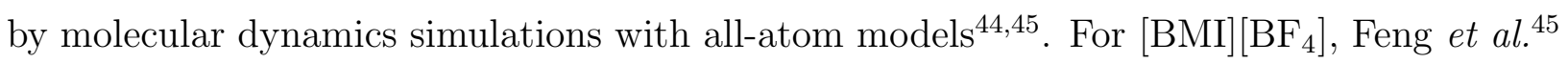
found capacitances around $6.7 \mu \mathrm{F} . \mathrm{cm}^{-2}$ for a constant charge of $\pm 10 \mu \mathrm{C} . \mathrm{cm}^{-2}$. While for $[\mathrm{EMI}]\left[\mathrm{BF}_{4}\right]$, Shim et al. ${ }^{44}$ give $\mathrm{C}_{-}=3.9 \mu \mathrm{F} . \mathrm{cm}^{-2}$ and $\mathrm{C}_{+}=11.0 \mu \mathrm{F} . \mathrm{cm}^{-2}$ for a constant charge of $\pm 6.9 \mu \mathrm{C} . \mathrm{cm}^{-2}$. We recall here that apart from the use of all-atom models to represent the ionic liquids, the main differences between our simulations and theirs are: i) the use of constant charges instead of constant potential differences and ii) the estimation of the capacitances as integral capacitances as opposed to differential capacitances (i.e. the capacitances are evaluated using one point charge only). As a consequence of the large charges used in the all-atom simulations and the calculation of the capacitance as an integral one, the estimated values may be out of the linear régime. Which, in addition to the fact that we employ a coarse-grained model, can be at the origin of the quantitative discrepancy between the results.

The coarse-grained models developed in this work generate the same capacitive behavior as for the $[\mathrm{BMI}]\left[\mathrm{PF}_{6}\right]$ ionic liquid ${ }^{18}$ and the simulations at constant potential differences allow us to gain insight on the influence of the ions on the electrode charging. The distributions of the carbon charges for $\Delta \Psi^{0}=0.0 \mathrm{~V}$ and $\Delta \Psi^{0}=1.5 \mathrm{~V}$ are given in figure 7 for the two ionic liquids studied here. Plots obtained for $[\mathrm{BMI}]\left[\mathrm{PF}_{6}\right]$ are added for comparison.

For the zero potential difference, we observe that the curve is not exactly centered around zero and that, while the shapes are very similar for $[\mathrm{BMI}]\left[\mathrm{PF}_{6}\right]$ and $[\mathrm{BMI}]\left[\mathrm{BF}_{4}\right]$, the results are different for $[\mathrm{EMI}]\left[\mathrm{BF}_{4}\right]$. This suggests that the nature of the cation influences more the charge distribution than the nature of the anion at zero potential. We notice that, for $\Delta \Psi^{0}=1.5 \mathrm{~V}$, the charges on the negative electrode are shifted toward negative values for $[\mathrm{EMI}]\left[\mathrm{BF}_{4}\right]$ compared to the other ionic liquids and that $[\mathrm{BMI}]\left[\mathrm{BF}_{4}\right]$ is intermediate between the other ionic liquids. On the positive electrode side, $[\mathrm{BMI}]\left[\mathrm{BF}_{4}\right]$ also appears as an intermediate between $[\mathrm{BMI}]\left[\mathrm{PF}_{6}\right]$ (values coincide for relatively low charges) and $[\mathrm{EMI}]\left[\mathrm{BF}_{4}\right]$ 

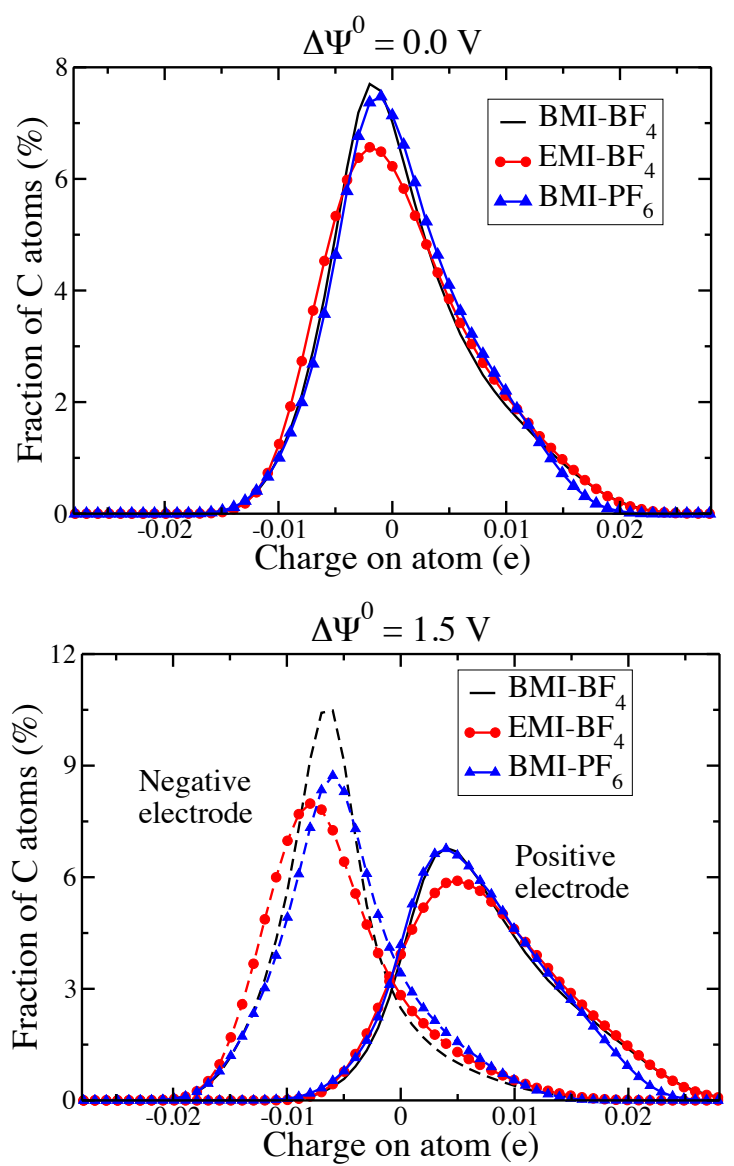

Figure 7: Distributions of the carbon charges on the positive and negative electrodes for three different ionic liquids and for $0.0 \mathrm{~V}$ and $1.5 \mathrm{~V}$ potential differences applied. The distributions are influenced by the nature of the ions.

(values coincide for relatively high charges).

A general feature, for the three ionic liquids, is the asymmetry between the positive and negative electrodes, with in particular, broader distributions on the positive side. This statement is consistent with the different geometries of anions and cations in our systems. The variations in the charge distributions show that the use of constant charges uniformly distributed, even if sufficient to recover the capacitances of a planar electrode / ionic liquid interface $^{18}$, leads to an important loss of information on the systems under examination. 


\section{CONCLUSION}

The aim of this work was to develop coarse-grained models for two commonly studied ionic liquids, namely $[\mathrm{BMI}]\left[\mathrm{BF}_{4}\right]$ and $[\mathrm{EMI}]\left[\mathrm{BF}_{4}\right]$, in order to simulate complex systems such as supercapacitors including explicitly the structure of the carbon electrodes. We show that the parameter sets we established lead to the prediction of a number of properties in good agreement with experimental and all-atom simulations data.

First, we calculated static bulk properties, the densities and radial distribution functions of the ionic liquids, demonstrating that the models perform well for these basic quantities. Then, we verified that the two models are also able to accurately predict dynamic bulk properties. Next, we used simulations of the ionic liquid / vacuum interfaces to estimate the surface tensions of $[\mathrm{BMI}]\left[\mathrm{BF}_{4}\right]$ and $[\mathrm{EMI}]\left[\mathrm{BF}_{4}\right]$ at $400 \mathrm{~K}$ which are consistent with experimental results ${ }^{42 \mid 43}$. Finally, we tested the behavior of the ionic liquids confined between graphite layers under various applied potential differences. The qualitative behavior of the systems is similar to the ones observed for equivalent setups 18 (184/45). These new coarsegrained models have thus proven their accuracy for a number of relevant properties which make them suitable for simulations of complex systems, such as supercapacitors, for which a high computational efficiency is needed on the ionic liquid side.

\section{ASSOCIATED CONTENT}

Supporting Information available: Densities, diffusion coefficients and viscosities calculated in this work, a snapshot of the liquid / graphite simulation cell and additional ionic density profiles. This material is available free of charge via the Internet at http://pubs.acs.org.

\section{ACKNOWLEDGMENTS}

We acknowledge the support of the French Agence Nationale de la Recherche (ANR) under grant ANR-2010-BLAN-0933-02 ("Modeling the Ion Adsorption in Carbon Micropores"). We thank Paul Madden for fruitful discussions. 


\section{REFERENCES}

1 Borodin, O. J. Phys. Chem. B 2009, 113, 11463-11478.

2 Yan, T.; Burnham, C. J.; Del Pópolo, M. G.; Voth, G. A. J. Phys. Chem. B 2004, 108, $11877-11881$.

3 Salanne, M.; Siqueira, L. J. A.; Seitsonen, A. P.; Madden, P. A.; Kirchner, B. Faraday Discuss. 2012, 154, 171-188.

4 Bhargava, B. L.; Balasubramanian, S. J. Chem. Phys. 2007, 127, 114510.

${ }^{5}$ Chaban, V. V.; Voroshylova, I. V.; Kalugin, O. N. Phys. Chem. Chem. Phys. 2011, 13, 7910 7920.

6 Dommert, F.; Schmidt, J.; Qiao, B.; Zhao, Y.; Krekeler, C.; Site, L. D.; Berger, R.; Holm, C. J. Chem. Phys. 2008, 129, 224501.

7 Shah, J. K.; Brennecke, J. F.; Maginn, E. J. Green Chem. 2002, 4, 112-118.

8 Pinilla, C.; Del Pópolo, M. G.; Kohanoff, J.; Lynden-Bell, R. M. J. Phys. Chem. B 2007, 111, $4877-4884$.

9 Shim, Y.; Kim, H. J. ACS Nano 2009, 3, 1693-1702.

10 Singh, R.; Monk, J.; Hung, F. R. J. Phys. Chem. C 2011, 115, 16544-16554.

11 Chmiola, J.; Yushin, G.; Gogotsi, Y.; Portet, C.; Simon, P.; Taberna, P. L. Science 2006, 313, $1760-1763$.

12 Lewandowski, A.; Galinski, M. J. Phys. Chem. Solids 2004, 65, $281-286$.

13 McEwen, A. B.; McDevitt, S. F.; Koch, V. R. J. Electrochem. Soc. 1997, 144, L84-L86.

14 Yang, L.; Fishbine, B. H.; Migliori, A.; Pratt, L. R. J. Am. Chem. Soc. 2009, 131, 12373-12376.

15 Shim, Y.; Kim, H. J. ACS Nano 2010, 4, 2345-2355.

16 Merlet, C.; Rotenberg, B.; Madden, P. A.; Taberna, P. L.; Simon, P.; Gogotsi, Y.; Salanne, M. in press, DOI: 10.1038/nmat3260.

17 Roy, D.; Maroncelli, M. J. Phys. Chem. B 2010, 114, 12629-12631.

18 Merlet, C.; Salanne, M.; Rotenberg, B.; Madden, P. A. J. Phys. Chem. C 2011, 115, 1661316618 .

19 Palmer, J.; Llobet, A.; Yeon, S.-H.; Fischer, J.; Shi, Y.; Gogotsi, Y.; Gubbins, K. Carbon 2010, 
48, 1116-1123.

20 Wang, Y.; Izvekov, S.; Yan, T.; Voth, G. A. J. Phys. Chem. B 2006, 110, 3564-3575.

21 Wang, Y.; Feng, S.; Voth, G. A. J. Chem. Theory Comput. 2009, 5, 1091-1098.

22 Liu, Z.; Wu, X.; Wang, W. Phys. Chem. Chem. Phys. 2006, 8, 1096-1104.

23 Zhong, X.; Liu, Z.; Cao, D. J. Phys. Chem. B 2011, 115, 10027-10040.

24 Bhargava, B. L.; Devane, R.; Klein, M. L.; Balasubramanian, S. Soft Matter 2007, 3, 1395-1400.

25 Bhargava, B. L.; L. Klein, M. Mol. Phys. 2009, 107, 393-401.

26 Cole, M. W.; Klein, J. R. Surf. Sci. 1983, 124, 547-554.

27 Martyna, G. J.; Klein, M. L.; Tuckerman, M. J. Chem. Phys. 1992, 97, 2635-2643.

28 Martyna, G. J.; Tobias, D. J.; Klein, M. L. J. Chem. Phys. 1994, 101, 4177-4189.

29 Siepmann, J. I.; Sprik, M. J. Chem. Phys. 1995, 102, 511-524.

30 Vatamanu, J.; Borodin, O.; Smith, G. D. J. Am. Chem. Soc. 2010, 132, 14825-14833.

31 Reed, S. K.; Lanning, O. J.; Madden, P. A. J. Chem. Phys. 2007, 126, 084704.

32 Pounds, M.; Tazi, S.; Salanne, M.; Madden, P. A. J. Phys.: Condens. Matter 2009, 21, 424109.

33 Tazi, S.; Salanne, M.; Simon, C.; Turq, P.; Pounds, M.; Madden, P. A. J. Phys. Chem. B 2010, $114,8453-8459$.

34 Noda, A.; Hayamizu, K.; Watanabe, M. J. Phys. Chem. B 2001, 105, 4603-4610.

35 Wong, C.-L.; Soriano, A. N.; Li, M.-H. 10 2008, 271, 43-52.

36 Tokuda, H.; Hayamizu, K.; Ishii, K.; Susan, M. A. B. H.; Watanabe, M. J. Phys. Chem. B 2004, 108, 16593-16600.

37 de Andrade, J.; Böes, E. S.; Stassen, H. J. Phys. Chem. B 2002, 106, 13344-13351.

38 Hayamizu, K.; Aihara, Y.; Nakagawa, H.; Nukuda, T.; Price, W. S. J. Phys. Chem. B 2004, 108, 19527-19532.

39 Salanne, M.; Simon, C.; Turq, P.; Madden, P. A. C. R. Chimie 2007, 10, 1131-1136.

40 Frenkel, D.; Smit, B. Understanding Molecular Simulation; Academic Press, Inc.: Orlando, FL, USA, 2nd ed., 2001.

41 Bresme, F.; González-Melchor, M.; Alejandre, J. J. Phys.: Condens. Matter 2005, 17, S3301S3307.

42 Ghatee, M. H.; Zolghadr, A. R. Fluid Phase Equilibr. 2008, 263, 168-175.

43 Shamsipur, M.; Beigi, A. A. M.; Teymouri, M.; Pourmortazavi, S. M.; Irandoust, M. J. Mol. Liq. 2010, 157, 43-50. 
44 Shim, Y.; Kim, H. J.; Jung, Y. Faraday Discuss. 2012, 154, 249-263.

45 Feng, G.; Huang, J.; Sumpter, B. G.; Meunier, V.; Qiao, R. Phys. Chem. Chem. Phys. 2011, 13, 14723-14734. 
Graphical abstract
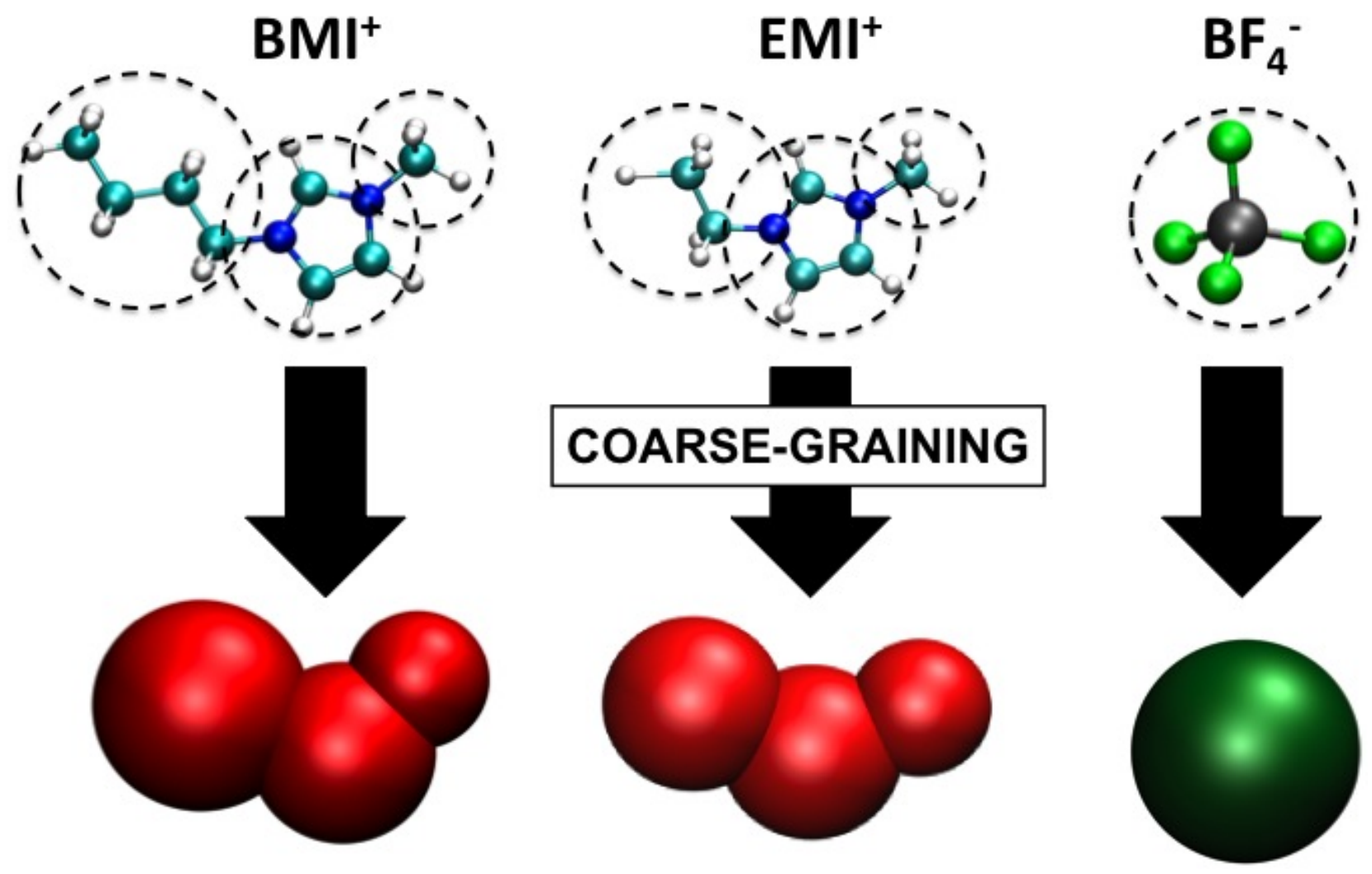